\title{
The Effects of Wet Cupping Therapy in Blood Pressure, Glucose, Uric Acid and Total Cholesterol Levels
}

\author{
Sutriyono $^{1, *}$, Muhammad Rodham Robbina ${ }^{2}$, Meksianis Zadrak Ndii ${ }^{3}$ \\ ${ }^{1}$ Department of Biology; ${ }^{2}$ Department of Mathematics, Faculty of Science and Technology, UIN Sunan Kalijaga, Yogyakarta, Indonesia \\ ${ }^{3}$ Department of Mathematics, Faculty of Science and Engineering, University of Nusa Cendana, Kupang-NTT, Indonesia \\ Author correspondency*: \\ sutriyono@uin-suka.ac.id
}

\begin{abstract}
Wet cupping therapy is a simple, cheap, and effective alternative medical treatment. In China wet cupping therapy become a formal treatment in the hospital. 14 centuries ago Prophet Muhammad implemented wet cupping therapy or hejamah as a curing treatment and become sunnah for muslim. Today in a modern world, many studies proved the advantages of wet cupping therapy, which is a sunnah since 14 centuries ago. The aims of this study were to measure the effects of wet cupping therapy treatment on blood pressure, blood glucose, uric acid, and total cholesterol level. 21 participants were treated with hejamah/wet cupping, blood pressure and blood samples were collected from all the participants one week before and one week after hejamah. Blood pressure, either systolic or diastolic was significantly decreased following therapy $(\mathrm{p}|<| 0.05)$, blood glucose had a slight decreased but not significant $(\mathrm{p}|>| 0.05)$. uric acid and total cholesterol level was also significantly decreased following therapy $(\mathrm{p}|<| 0.05)$. With only just one time treatment, hejamah had a significant effects on blood pressure, uric acid and total cholesterol level, that is proved the advantages of hejamah.
\end{abstract}

Keywords: Hejamah; wet cupping therapy; cardiovascular diseases; hematology; blood pressure; blood glucose; uric acid; cholesterol

\section{INTRODUCTION}

Cardiovascular diseases are major health problems and they are associated with mortality and morbidity (Refaat et al, 2014). The World Health Organization (WHO) has reported that cardiovascular diseases are responsible for $30 \%$ of all deaths, which is equivalent to the combined death rates associated with several other medical conditions (Rehm et al, 2009). The estimated number of death due to cardiovascular diseases by the WHO is 17.3 million people per year and the number is expected to increase to 23.3 million/year in 2030 ( $\mathrm{Ng}$ et al, 2012).

Several benefits of Complementary Medicine/Alternative Medicine, also known as traditional medicine, have been shown and it is effective in the prevention of disease, treatment of noncommunicable diseases, and improvement of the quality of life for persons living with chronic diseases (Burge and Albright, 2002). The WHO has been encouraging the implementation of traditional medicine since many patients are not satisfied by the outcomes of modern medicine particularly those related to chronic diseases (WHO, 2002). One of the alternative medicines is Islamic hejamah/wet cupping.

In the middle east, Arabic writers report that cupping therapy dates back to 3500 B.C. (5500 years ago), where Assyrians were the first Arab population to use primitive tools as animal horns and bamboo wood for cupping therapy then the Chinese physician, Jee Hong (381- 281 B.C.) was among the leaders in that art. Arabic civilization termed cupping therapy, Al-hijamah therapy (which means in Arabic to restore to the original size), where it was used in treating hypertension, polycythemia, headache, migraine and drug intoxication. They diagnosed polycythemia whenever there was an exaggeration of the pink color of the skin (Omar, 2009). Interestingly, venesection (phlebotomy) is still being used currently in hospitals for treating polycythemia, where blood is drawn out and is replaced by saline infusion (McMullin et al, 2005).

Cupping therapy is being practiced nowadays in many countries all over the world including Germany, Norway, Denmark, Saudi Arabia, Egypt, India, China and other countries. German people are familiar with cupping therapy (Michalsen et al, 2009) and so are Danish and Norwegian peoples where those European societies already have a shift in attitude to include complementary medicine within the conventional health care system (Salomonsen et al, 2011). The exact origin of cupping therapy is a matter of controversy. Chinese scientists report in their literature that cupping therapy is a part of the traditional Chinese medicine dating back to at least 2,000 years (Chirali, 2014).

\section{MATERIALS AND METHODS}

This study was a true experimental research. 21 adult men were recruited into the study, wet cupping was performed on the study subjects one time according to 
Islamic protocol, the subject were asked to be fasting at least 3 hours before the initiation of the procedure. Blood pressure and blood sample were obtained from the subject before the procedure. We run a test to the blood sample to measure blood glucose, uric acid, and total cholesterol level. A second blood pressure and blood sample were obtained from the subjects 7 days after wet cupping therapy.

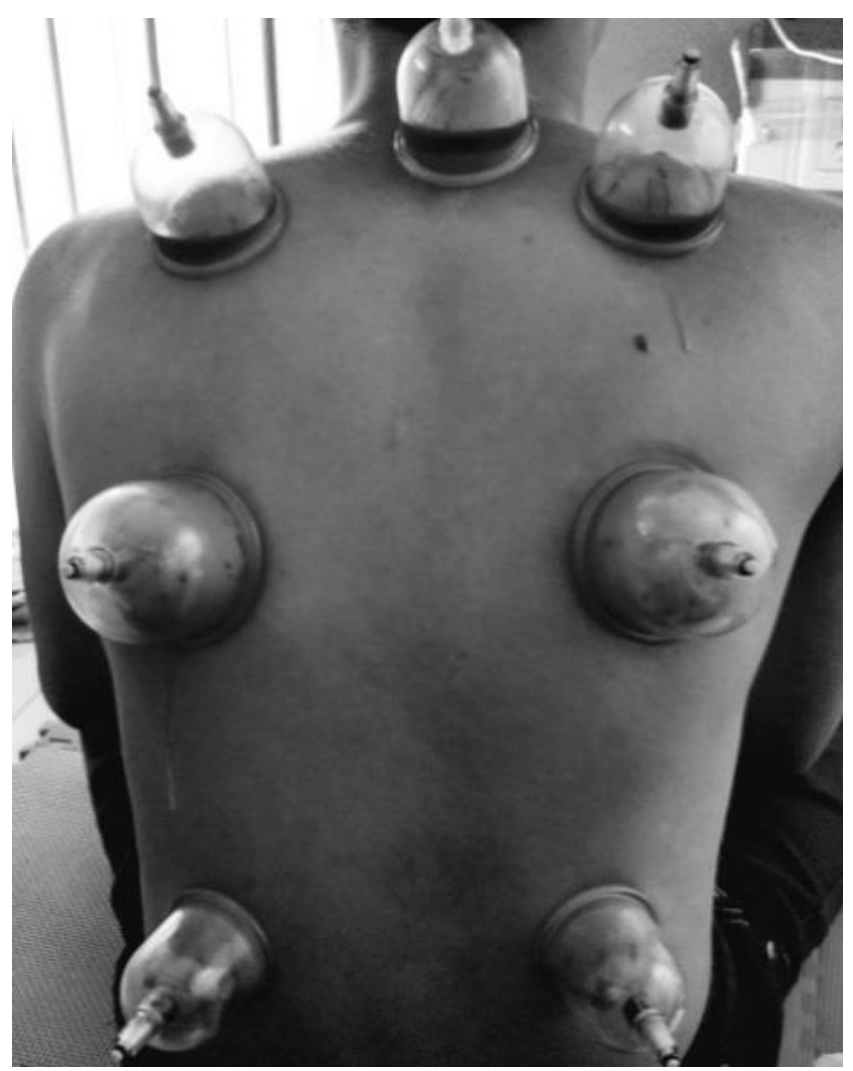

Figure 1. Wet cupping therapy.

Wet cupping therapy were performed using seven points on the back of each subjects, the cup was sterilized using alcohol. The cups were placed on the chosen sites and a negative pressure was created by manual suction using the provided pump with the kit. The cups were left for a period of 7-10 minutes after ensuring their firm attachment to the skin. The cups were removed and 12-15 superficial incisions were made on each chosen area of the skin using sterile surgical blades. After soaking the cups, they were replaced back on the chosen areas of the skin and negative pressure was created as previously described. The cups were left on the skin till they were filled with blood from the capillary vessels. The cups were removed approximately after 3 minutes and new cups were placed on the same areas as previously mentioned. The used cups were socked in betadine solution for sterilization. The process of blood-letting was repeated for two times in total.

\section{RESULT AND DISCUSSION}

Statistical analysis was performed using SPSS version 15. Normality and homogeneity of data were assessed with the Shapiro-Wilk test.

Table 1. The effect of wet cupping therapy to blood pressure.

\begin{tabular}{lll}
\hline & Mean $(\mathbf{m m H g})$ & $\boldsymbol{P}$ \\
\hline Systolic & 132.33 & \\
Pretest & 124.81 & 0.001 \\
Posttest & & \\
\hline Diastolic & 86.29 & 0.001 \\
Pretest & 81.19 & \\
Posttest & & \\
\hline
\end{tabular}

According Table 1 that using $\mathrm{t}$ test showing that there is a different on blood pressure (systolic and diastolic) between before the wet cupping therapy and after the wet cupping therapy. There is some reduction on the mean of systolic pressure in amount of $7.5 \mathrm{mmHg}$ from $132.33 \mathrm{mmHg}$ becomes $124.81 \mathrm{mmHg}$, while for the diastolic pressure there is some reduction in amount of $5.1 \mathrm{mmHg}$ from $86.29 \mathrm{mmHg}$ becomes $81.19 \mathrm{mmHg}$. The analysis result using t test to systolic pressure and diastolic pressure showing the $\mathrm{p}$ value is 0.001 $(\mathrm{p}|<| 0.05)$, then the effect of wet cupping therapy to the reduction of subjects blood pressure after wet cupping therapy is significant. The study of Refaat et al (2014) showing the same result that wet cupping therapy can reduce blood pressure significantly.

The positive effect that given by wet cupping therapy into the reduction of blood pressure is because wet cupping therapy has benefit to remove all waste and sediment in blood artery that connected to the circulation of blood (ICA, 2011). The blood pressure reduction also happen because wet cupping therapy in a skin (cutaneous), under skin tissue (sub-cutaneous), fascia, and the muscle will cause the damage of mast cell, the result of this damage will release a few substance like serotonin, histamine, bradikin, slowreacting substance (SRS), and few other substance, this substance will cause capillar and arteriole dilatation also flare reaction in the place of wet cupping therapy point. Capillar dilatation also happen in a place who far from wet cupping therapy point, this is cause the blood artery microcirculation repair, then will show relaxation effect in clumsy muscle also because of vasodilatation will reduce blood pressure (Refaat et al, 2014)

Table 2. The effect of wet cupping therapy to blood glucose.

\begin{tabular}{lll}
\hline Blood Glucose & Mean $\left(\mathbf{m g d L}^{-\mathbf{1}}\right)$ & $\boldsymbol{p}$ \\
\hline Pre-test & 98.48 & 0.311 \\
Post-test & 93.33 & \\
\hline
\end{tabular}

According to Table 2 that using $t$ test, it is showing that there is a different on blood glucose level between 
before wet cupping therapy and after the wet cupping therapy. There is some reduction on the mean of blood glucose level between before wet cupping therapy and after the wet cupping therapy in amount of $5.15 \mathrm{mgdL}^{-1}$ from $98.48 \mathrm{mgdL}^{-1}$ becomes $93.33 \mathrm{mgdL}^{-1}$. The analysis result using t test to blood glucose level showing the $\mathrm{p}$ value is $0.311(\mathrm{p}|>| 0.05)$, then the effect of wet cupping therapy to the reduction of subjects blood glucose level after wet cupping therapy is not significant, even though the effect of wet cupping therapy still make some reduction on blood glucose level.

Wet cupping therapy enhances insulin sensitivity in healthy subjects with normal glucose levels and normoferritinemia (Vakilinia et al, 2016). Bleeding due to hijamah was found to decrease glucose serum and triglycerides in patient with diabetes (Lowe, 2017). Some study has proved the efficacy of wet cupping therapy, on of it is the study by Farahmand et al (2012), this study prove that wet cupping therapy an diet have significant effect to lipid profile improvement. Another study about efficacy of wet cupping therapy is the study by Refaat et al (2014) who mention that wet cupping therapy has positive effect to blood glucose level on subject who has diabetes mellitus disease.

Table 3. The effect of wet cupping therapy to uric acid

\begin{tabular}{lll}
\hline Uric acid & Mean $\left(\mathbf{m g d L}^{-\mathbf{1}}\right)$ & $\boldsymbol{P}$ \\
\hline Pretest & 7.15 & 0.001 \\
Posttest & 5.91 & \\
\hline
\end{tabular}

According to Table 3 that using t test showing that there is a different on uric acid level between before wet cupping therapy and after the wet cupping therapy. There is some reduction on the mean of uric acid level between before wet cupping therapy and after the wet cupping therapy in amount of $1.24 \mathrm{mgdL}^{-1}$ from 7.15 $\mathrm{mgdL}^{-1}$ becomes $5.91 \mathrm{mgdL}^{-1}$. The analysis result using $\mathrm{t}$ test to uric acid level showing the $\mathrm{p}$ value is 0.001 $(\mathrm{p}|<| 0.05)$, then the effect of wet cupping therapy to the reduction of subjects urid acid level after wet cupping therapy is significant. This Reduction is positive enough to prevent cardiovascular disease because high level of uric acid or commonly called hyperuricemia according to Euser et al (2008) can rise the risk of cardiovascular disease.

Table 4. The effect of wet cupping therapy to total cholesterol.

\begin{tabular}{lll}
\hline Cholesterol & Mean $\left(\mathbf{m g d L}^{-\mathbf{1}}\right)$ & $\boldsymbol{p}$ \\
\hline Pretest & 177.05 & 0.022 \\
Posttest & 160.43 & \\
\hline
\end{tabular}

According to Table 4 that using t test showing that there is a different on total cholesterol level between before wet cupping therapy and after the wet cupping therapy. There is some reduction on the mean of total cholesterol level between before wet cupping therapy and after the wet cupping therapy in amount of 16.62 $\mathrm{mgdL}^{-1}$ from $177.05 \mathrm{mgdL}^{-1}$ becomes $160.43 \mathrm{mgdL}^{-1}$. The analysis result using $\mathrm{t}$ test to total cholesterol level showing the $\mathrm{p}$ value is $0.022(\mathrm{p}|<| 0.05)$, then the effect of wet cupping therapy to the reduction of subjects total cholesterol level after wet cupping therapy is significant. The reduction of total cholesterol level has shown the effect of wet cupping therapy to total cholesterol level, which mean that if wet cupping therapy is doing regularly, wet cupping therapy can be alternative treatment beside conventional treatment for stroke patients to reduce total cholesterol level.

The reduction of total cholesterol level after wet cupping therapy is because there is some effect from hematology system mechanism who give main effect through the regulation system pathways of coagulantanticoagulation with the improvement of blood flow and organ oxygenation (Ahmadi et al, 2008). Considering hepar is a place that blood filtration from various toxic substances who entering the body happen, through $t i=$ his hematology system mechanism and immune system mechanism the total cholesterol level can be reduced (Ahmadi et al, 2008).

However, there are some consideration that need to be consider. First the sample we were taken is small, and we didn't consider the health factor of subjects of this study. Second, in the process of our study we didn't consider factors who maybe have a big impact to this study, like subjects diet, sleep patterns, etc.

Despite the shortcomings of this study, hejamah has been proven have some benefits in the prevention of cardiovascular diseases. Study of Bassem Refaat (2014) shown that although hejamah have no significant impact on decreasing total cholesterol level, but significantly raised HDL (High Density Lippoprotein) level and decreased LDL (Low Density Lippoprotein) level. With lower LDL level can lower the risk of stroke attack.

\section{CONCLUSION}

Overall, wet cupping therapy is a traditional treatment that is a sunnah from Prophet Muhammad.

First the sample we are taken is small, and we didn't consider the health factor of subjects of this study. Second in the procces of our study we didn't consider factors who maybe have a big impact to this study, like subjects diet, sleep patterns, etc.

Despite the shortcomings of this study, hejamah has been proven have some benefits in the prevention of cardiovascular diseases. Study of Bassem Refaat (2014) shown that although hejamah have no significant impact on decreasing total cholesterol level, but significantly raised HDL (High Density Lippoprotein) level and decreased LDL (Low Density Lippoprotein) level. With lower LDL level can lower the risk of stroke attack.

The conclusion is hejamah or wet cupping theraphy have a great chance to become a medical treatment who 
can reduce blood pressure, blood glucose level, urid acid level, and total cholesterol level. Hejamah also can prevent cardiovascular diseases because it can raise the level of HDL and reduce the level of LDL.

\section{REFERENCES}

Ahmadi, A., Schwebelb, D. C., \& Rezaei, M. 2008. The Efficacy of Wet-Cupping in the Treatment of Tension and Migraine Headache. The American Journal of Chinese Medicine, 36(01), 37-44.

Burge S. K., Albright T. L., \& Residency Research Network Of South Texas (RRNeST) Investigators. 2002. Use of complementary and alternative medicine among family practice patients in south Texas. American Journal of Public Health 92.10: 1614- 1616.

Chirali, I. Z. 2014. Traditional Chinese Medicine Cupping Therapy. Elsevier Health Sciences.

Euser, S. M., Hofman, A., Westendorp, R. G. J., \& Breteler, M. M. (2008). Serum uric acid and cognitive function and dementia. Brain 132(2), 377-382.

Farahmand, S. K., Gang, L. Z., Saghebi, S. A., Mohammadi, M., Mohammadi, S., Mohammadi, G., \& Ghayour-Mobarhan, M. 2012. The Effects of Wet Cupping on Coronary Risk Factors in Patients with Metabolic Syndrome: A randomized Controlled Trial. The American Journal of Chinese Medicine, 40(02), 269-277.

Indonesian Cupping Association. 2011. Standard Operating Procedure Hejamah. Bogor: Research and Development Division ICA.

Ng, N., Johnson, O., Lindahl, B., \& Norberg, M. 2012. A reversal of decreasing trends in population cholesterol levels in Västerbotten County, Sweden. Global Health Action, 5(1), 10367.

Lee, M. S., Choi, T. Y., Shin, B. C., Kim, J. I., \& Nam, S. S. 2010. Cupping for hypertension: a systematic review. Clinical and Experimental Hypertension 32(7), 423-425.
McMullin, M. F., Bareford, D., Campbell, P., Green, A. R., Harrison, C., Hunt B., \& Ryan, K. 2005. Guidelines for the diagnosis, investigation and management of polycythaemia/ erythrocytosis. British Journal of Haematology 130(2), 174195.

Michalsen, A., Bock, S., Lüdtke, R., Rampp, T., Baecker, M., Bachman, J., \& Dobos, G. J. 2009. Effects of traditional cupping therapy in patients with carpal tunnel syndrome: a randomized controlled trial. The Journal of Pain 10(6), 601608.

Omar, S. A. H. 2009. Al-hijamah (cupping therapy): Sunnah and therapy. Dar Ommah for publication, Jeddah.

Refaat, B., El-Shemi, A. G., Ebid, A. A., Ashshi, A., \& BaSalamah, M. A. 2014. Islamic Wet Cupping and Risk Factors of Cardiovascular Diseases: Effects on Blood Pressure, Metabolic Profile and Serum Electrolytes in Healthy Young Adult Men. Alternative and Integrative Medicine, 3(1): 151 .

Rehm, J., Mathers, C., Popova, S., Thavorncharoensap, M., Taerawattananon, Y., \& Patra, J. 2009. Global burden of disease and injury and economic cost attributable to alcohol use and alcohol-use disorders. The Lancet 373(9682), 2223 2233.

Salomonsen, L. J., Skovgaard, L., LaCour, S., Nyborg, L., Launs $\varnothing$, L., \& Fonnebo, V. 2011. Use of complementary and alternative medicine at Norwegian and Danish hospitals. BMC Complementary and Alternative Medicine, 11(1), 4.

Vakilinia, S. R., Bayat D., \& Asghari, M. 2016. Hijama (Wet Cupping or Dry Cupping) for Diabetes Treatment. Iranian Journal of Medical Sciences 4(3 Suppl), S37.

Lowe, D. T. 2017. Cupping therapy: An analysis of the effects of suction on skin and the possible influence on human health. Complementary Therapies in Clinical Practice, 29, 162-8.

WHO. 2002. WHO Traditional Medicine Strategy 2002-2005. World Health Organization, Geneva, Switzerland. 